gave great relief in the second case and may be used to diminish the intense headache which often accompanies the development of albuminuric retinitis. The sphygmograph readily reveals the action of the drug and may be employed to indicate the amount and frequency of the dose required to mitigate the tension. I say "mitigate" advisedly, for to relieve the symptoms it is not necessary, nor, indeed, is it an easy matter, to establish a normal tension. A tabella every six or eight hours is usually sufficient to accomplish the desired end. In one case of cardiac asthma with very irregular high-tension pulse the relief given by the nitrites was so great that the patient was immediately transferred from his bed to the local races, and the latter end of that man was worse than the first. As his medical attendant observed, the treatment both cured and killed him. Sometimes the nitrites produce definite diuresis, but even this should not lead us to set aside other eliminatory measures. When the kidneys fail the skin presents a large and active secretory area second only in importance to the mucous membrane and glands of the alimentary tract. The fact that in Bright's disease urea is excreted by the skin is a definite indication to the therapontist. Of every-day drugs the sweet spirit of nitre and the acetate of ammonia are the most popular and valuable diaphoretics, but in uræmia we are compelled to adopt more active measures, such as the external application of heat, wet or dry, and the hypodermic injection of pilocarpine. The hot pack is one of our most valuable remedles and available in almost all cases. It is, however, to be specially selected when calomel and venesection are out of the question, when the system generally, and the connective tissues in particular, are drowned in ureated liquid and when the brain disturbance is more dependent on direct intoxication than irregularities of arterial pressure ; in other words, in the dropsical uræmias of blocked or bankrupt kidneys.

The employment of pilocarpine hypodermically is not without its dangers. Nevertheless, if other remedies fail, it may be tried, provided the patient possesses full power of deglutition and the thoracic organs are in good conditon. Its action should be assisted by the use of hot blankets, ot bottles, and warm drinks. Usually the response of the skin is rapid, a few minutes sufficing to start the perspiration, but the response of the system is somewhat more uncertain in time and degree. The effect produced, however, in some cases, as in the second already referred to, is very striking. Personally I avoid the use of the drug if possible, but confess that I have not tried the method of inanction recommended in milder cases by some writers with the object of reducing the risk of cardiac collapse and pulmonary odema to a minimum. As pilocarpine is recommended in some forms of insanity it may be interesting to add that $m y$ friend Dr. Wansbrough Jones after the hypodermic injection of $\frac{1}{3} \mathrm{gr}$. for ocular disease witnessed the immediate development of acute melancholia with attempted suicide, and the repetition of the dose some time later at the recommendation of the oculist led to a similar disturbance followed by several months' detention in an asylum. As there was no family history to suggest such a complication the drug was naturally suspected. At any rate the dangers of pllocarpine are sufficiently real to render its use a matter for deliberation. Many other interesting points in the treatment of uræmia press for discussion but time forbids. My object is accomplished if I have left on your minds the impression that so-called uræmic convalsions and coma have not necessarily the serious prognosis usually accorded them; that they may occur apart from evident organic disease ; that even in Bright's disease they may prove to be mere accidents by the way; and, lastly, that the value of treatment is often greatest in old age, when the physician is in danger of standing by to watch the curtain fall before the drama has really reached the finale.

Manchester.

ON Wednesday evening, May 25th, a conversazione of the St. Andrews Graduates' Association was held at 11, Chandos-street, Cavendish-square. The company was received by the President, Dr. William F. Cleveland, and Miss Cleveland, assisted by the Vice-president, Sir Charles Gage Brown, and others. There was a large gathering of members and their friends, and an excellent selection of vocal and instrumental music was given under the direction of Dr. Cooper Key, of Wilton-place, a member of the council of the association.

\section{MALARIAL FEVER: SOME SUGGES- TIONS IN ITS PATHOLOGY AND TREATMENT.}

BY WilliaM FORBES-LeSLIE, M.B., C.M. ABERd.

DURING the last few months malaria has appeared as a plague at Batum and in other districts of Asiatic Russia, causing a dreadful mortality, and the losses of the Spanish army in Cuba from the same cause, which $I$ have reason to believe may be placed at nearly 100,000 men, with the death of Sir William Maxwell and others, make this, so it seems to me, an opportune moment for its discussion. My experience of the disease, extending as it does over a period of nearly twenty years, may, I hope, give me a certain authority for the statements I am about to make and lend weight to the observations which have led me to conceive a new pathology and treatment for it. Malaria for centuries has been recognised as the fever which infected marshy and tropical districts. It bas during this long period received many names according to the type in which it manifested itself. There are certain parts of the world where it is more common than in others and where it is most deadly; such a part is the west coast of Africa, Kast Africa, and Madagascar, and it is the malarias of these countries, especially of the latter two, which I wish to discuss. Malaria is endemic, that is, it is confined to certain districts, and has no power to spread beyond its natural zone of production. Some observers are inclined to grant it an epidemic power, and this I believe it has in certain of its independent forms, such as influenza, malarial cholera, yellow fever, and dengue in all forms arising from and particularised from the parent disease. It has the tendency to widely extend itself beyond its seat of origin by winds, rivers, and sea-currents, to be deflected by forests, perpendicular cliffs, and to be impelled obliquely along slopes from the earth to the upper air-currents. It has a great attraction for the earth, which prevents it rising perpendicularly as do the more volatile matters of evaporation. I have noticed that according to its methods of transmission so it differs in the symptoms it produces. Thus if drunk in water or taken in food it gives rise to algid forms. If inhaled in the district itself it gives rise to a continued' type frequently terminating in hyperpyrexia, but if inbaled at sea to an irregular type, characterised by intermittent fever, ague, or enteritis. I cannot see that Dr. Manson has proved that the mogquito is the intermediary between the malarial germ in the soil and that found in the human blood. The poison itself is said to be an organism, and this can hardly be doubted, but its form and method of development are not yet understood. Italian observers lay claim to its discovery. Their experiments have been made on Roman fever. It is not singular, therefore, if other observers contest this organism and lay claim to have discovered another which they say is always found in the blood in malaria. The difference in the fever of the Roman marshes from the Chinese and Indian fevers is most marked and my experience in Africa alone has taught me that the fever of no district resembles another, bat they differ in some instances as widely as typhoid fever from cholera. Indeed, one could make a fever map of the African continent as uniform in its areas as the counties of England appear on a school atlas. Observers have tabulated such a number of bizarre forms of the organism in the blood that one gets confused and doubtful as to their identity and rather inclines to the belief that they are abnormal elements of the blood changed by some chemical action of the poison than individual organisms. My opinion is that the true germ of malaria has not yet been discovered and will not be till we can obtain a higher power of the microscope. As every district has a fever differing clinically, so must every fever be produced by a different and modified organism. How can we say definitely, then, Here is the organism of malaria? Rather say, Here are a score of organisms which produce malaria. We are only on the threshold of our knowledge of its life-history. Another fact I have observed is its power to produce other diseases. In this it somewhat resembles syphilis; but I cannot help thinking there may be some relationship between the two. In all malarial districts wo find syphilis in its worst form, and in Madagazcar it is so 
common that bat one adult native ont of ten has not had it or is not suffering from it. Then we know that syphilis came from the east. The poison of malaria is an elastic poison. It is not only changed by difference of district and atmosphere, but by constitutional idiosyncrasies. We must read a malarial origin in pneumonia, typhoid fever, cholera, dysentery, enteritis, yellow fever, malignant endocarditis, multiple neuritis, locomotor ataxy, myelitis, meningitis, lunacy, hepatic troubles, kidney disease, blood diseases, skin diseases, and a host of others, not forgetting the bleeding diathesis. We must be prepared to recognise and treat these, not by the ordinary routine, but by that which applies to malaria, the initial disease and origin of them. It is wonderful to think that a poison can be so mobile as to be capable of change to such an extent. It naturally leads one to a belief that disease can only be impelled along certain planes and that under certain stimulation the tissues react in a certain manner. Another interesting fact in African fevers is that the sequelæ are far less in extent and severity in the algid than in the low forms. Thus we get serious impairment of motor or sensory paths, such as multiple neuritis, locomotor ataxy, migrating neuritis, sclerosis of the cord, paraplegia, hemiplegia, meningitis, meningeal and cerebral hæmorrhage, epilepsy, and diseases of the heart, liver, spleen, and kidneys. There is a great similarity between forms of malaria and influenza. It is natural, as it were, for one to telescope into the other. An attack of influenza will terminate in malaria or the reverse. And I have often noticed that malaria may infect with influenza, so that in this way malaria may originate an epidemic energy. It is quite in line with present opinion that influenza is a hybrid of malaria, for it is conceivable when we consider the mobility of the poison, its proneness to change with a change in its environment, and the fact that as disease is now undoubtedly proved to be the product of organic life that this life should be dominated by the law subserving life in the other departments of nature, and that the law of ascent is as applicable to the organisms of disease as to the organism of man.

We have now arrived at a stage when it is possible to determine the laboratory of the poison. It is necessary in every specific disease that it should have a nidus suitable to its development. Most observers in malaria have placed this in the blood. They say that once having gained entrance to the blood-stream it finds the necessary material for development and sets up a train of symptoms which are the clinical parallel of that development. Klebs was the first to demonstrate this theory by the discovery in the blood of an organism which he believed to be that of malaria. But it is obvious that there must be many organisms in the blood which from our imperfect microscopical powers have escaped notice; and also with a poison so powerful as malaria there must be a corresponding change in the elements of the blood with the production of bizarre forms, the difference between which and the latter is so slight in some cases, if any, as to render a decision difficult if not impossible.

It has been a matter of considerable dispute in what manner the poison obtains entrance into the system. Laveran and older anthorities held that it did so through the drinking water, others again believe that it is inhaled, and lately Dr. Manson has come forward with a theory that it enters the blood directly through the agency of mosquitoes. I believe it is possible for it to enter in all these ways. But its introduction by water through the prime vie is undoubtedly the most frequent method and the most fatal. In almost all the severe cases of algid malarias I have treated the poison has been, as far as I could ascertain, introduced in this manner. So long as the water is boiled, the fruit fresh, and the other natural conditions of health fulfilled, there will be no algid malarias. Dr. Manson's observations have been principally taken from Chinese and Indian malarias. He hypothecates a parasitic cycle such as one finds in certain other diseases. He then goes on to prove this hypothesis by demonstrating similar organisms in the mosquito and malarial blood. The mosquito may in many cases become an accidental medium, but that it is a necessary intermediary is not borne out by facts. It is highly probable that mosquitoes absorb the malarial germ during their aquatic life and that it is possible to introduce such into the human blood, but whether the organism so introduced can set up the disease in healthy blood is not proved. It is not certain that infected blood from one person can produce the disease in another. If there is, as Dr. Manson believes, a parasitic cycle, such introduction must necessarily break that cycle, because it is not only necessary for the organism to change as the development proceeds, but a change must take place in the blood to fulfil a further development in the organism. Further, to look at it practically, how can Dr. Manson explain the reason why persons are attacked at sea by fever who bave never been bitten by mosquitoes and who have never been before to a tropical country? I have seen hundreds of such cases. How is it that all the passengers on that side of the vessel nearest the coast have been seized by fever and the remainder on the other side escape. Surely it is not possible to believe that only these were bitten by mosquitoes and the rest were not. Is it not more conceivable and in line with its diffusion to believe that trade winds blowing off the coast carried the poison against that side of the vessel and that it was inhaled by the passengers whose cabin windows were open, but following a law of its diffusion which prevents its rising perpendicularly, was repelled by the side of the ship and obliged to ascend obliquely over it? We can divide most diseases into those arising from organisms in the blood and those arising from the introduction into the blood of the developmental products of organisms ontside the blood. Under which class does malaria enter? It is generally beljeved that it is under the first that we must place it. I entered the field of practical observation equipped with this theory, but my experience after a time led me to. modify my belief and I bave now altogether changed it. I cannot bring myself to consider malaria other than the result of the products of the developmental energy of the organism outside the blood-stream, and some of the facts which have led me to this belief are that preceding the fever there is invariably a stage of hepatic congestion and signs of bile in the blood; the proneness of the disease to attack the prime vice, as evidenced by gastric derangement, enteritis, aysentery, and typhoid fever; the peculiar liability of the liver to acute inflammation with abscess as an extension from the prima via; the induction of the algid malarias through the primee via; the success of a treatment which aims at sweeping out the intestinal tract and disinfecting it ; chills and rigors preceding the rise of temperature, with alternating falls and sweating; and the periodic type of the disease with alternations of health and disease. We know that constipation and other bowel derangements will cause stagnation of kile with increased absorption into the blood and that in this condition the constitution is more liable to disease than at any other time. We know also that by an energetic action by purgatives we can cleanse the prime vie, promote the natural passage of bile, and filter that already in the blood partly through the intestinal walls and by the kidneys. Now we know of no organism which fulfils part of its life history in the human blood which gives rise to such symptoms as are invariably found as a part of this disease except perhaps dengue - but dengue is only malaria under another name-and relapsing fever, which bears a close relationship to it. Idiopathic cases of pyæmia are so like malaria that it is often impossible to distinguish them. But this only bears out the fact that malaria, like pyæmia, is an extraneous disease. If we grant the extraneous life of the parasite then where is its place of development? Like pyæmia it must have a laboratory. I have no doubt that the laboratory is in the intestines, and that from here the poison dispenses its products either as spores, such as those bodies in the form of spheres, crescents, \&c., which have already been discovered in malarial blood, ox. intercellular elements, or as a ferment to the blood-stream just as diphtheria finds a suitable nidus in the tonsil and distribates its poison from thence. It is also certain that the liver has an influence upon its development. Derangement of the biliary functions is always present before an attack. But such a condition can be observed before all diseases of the intestinal tract, showing the intimate relation between the liver and the prime vire and the tendency to inflammation spreading upwards to the liver. It is interesting to observe that Lauder Brunton attributes some importance to the liver in connexion with the arrest of certain substances absorbed from the alimentary tract whereby they are either destroyed, stored up, or it may be prevented from entering the general circulation in too large amount and that ptomaines may be arrested in this way. To understand the functions of the liver we must remember its anique relation to the vascular 
and digestive systems, whereby many of the products of gastric and intestinal digestion have to traverse it before reaching the blood. The process of intestinal digestion is largely due to organisms and it is possible that many of these reach the liver with the material they have acted upon. But there are also organisms of disease which as accidental guests in the intestines also reach the liver. If the liver had no function of this sort the blood must be invaded by hordes of organisms or their products. It is necessary that a filter should exist between the alimentary canal and the circulation and it is natural to look for it in the liver. If this be true, infectious diseases must be preceded by hepatic derangement. Is this the case? It is invariably the case that disturbance of the hepatic functions ushers in infectious or endemic diseases. It is generally believed that at such times the blood is less powerfully phagocytic, but it towards organisms and ptomaines is lost. It is difficult to understand how ptomaines are destroyed in the liver. H. Rogers, as quoted by Landois and Stirling, says that it only possesses this property so long as it retains glycogen. Animal starch or glycogen is a true carbohydrate. It is stored up in the liver cells as amorphous crystals; its mother substance is the carbohydrates of the food; it is increased by large quantities of starchy matters, milk, fruit, and cane sugar; it is diminished enormously by a purely albuminous or fatty diet, by forced muscular movements or fatigue, exposure to cold, by hunger or by anything which disorders the biliary functions.

Now let us look at the conditions which induce malarial fever. They are identical with those which diminish glycogen-e.g., purely albuminous or fatty diet, fatigue, exposure to cold, hunger, or anything which tends to the formation of acid, a derangement of the biliary functions, while on the other hand those whose diet consists largely of carbohydrates are usually the persons who escape fever. Let us turn for a moment to the subject of glycosuria. This is a condition characterised by the presence of grape sugar in the urine, which Dr. Pavy holds is due to the liver being deficient in glycogen from a fault in its glycogenic functions. If this be so, then a person suffering from diabetes is unduly susceptible to malaria, which is the case. The exciting causes of glycosuria are, broadly speaking, the exciting causes of malaria, and the fatal effects of opinm in malaria may have something to do with its action on the hepatic vaso-motor nerves, whereby it diminishes the formation of glycogen. These facts, I think, go far towards proving that the liver has a peculiar function with regard to ptomaines, retaining, destroying, or utilising them in its metabolism, and that this power depends upon the amount of glycogen in the liver. The latency of malaria may depend upon the retention of the ptomaines in the liver till such time as functional derangement permits their access to the circulation. In every disease with the absorption of poisons there comes a time when the phagocytic action of the blood is neutralised, and even, though the absorption is stopped, the system fails to recover itself. But before this point is reached malaria will exhaust itself by the natural channels. The fact that irritation of the urinary tract is a common feature in fever goes far to prove this. That the poison remains in the blood is highly improbable. The keenest observers have failed to discover it therein. But directly there is an imprudence in the diet whereby the glycogen is diminished then the fever manifests itself. The effect of chills inducing an attack strengthens the hypothesis, for we know that in hot climates the glycogenic functions are profoundly affected by changes of temperature. If we have come to this conception of the pathology of malaria by observing its clinical features, we shall be further strengthened in it by the favourable effect of a treatment based upon this conception. Heretofore physicians have been satisfied in trying to destroy the organism in the blood, but it is difficult to reach the blood with drugs; they have first to pass through the various chemical processes in the laboratory of the body which have power almost invariably to split them into their radicals. The present treatment of malaria may be conveniently divided into the specific and non-specific. The former is held by the mass of the profession, the latter by only a few. The doctrine of specifics is present in the traditions of medicine from the earliest times and it is natural to beliere that in the great economy of nature there is a remedy for every disease. Consequently when quinine was discovered to have a favourable effect on malaria it was at once conceived to have a specific action. That it has a favourable effect is beyond doubt, but a specific action would intimate that it cures the disease-which it certainly does not. I have come to this conclusion from a study of both the Indian and African fevers. The method of giving quinine in large and frequent doses is sometimes a source of danger; it may in strong constitutions cut short an attack of ague, but in the deadlier forms of malaria it is most pernicions. I have seen better results attend the administration of simple remedies aiming at alleviating the symptoms. The great Dr. Livingstone came nearer the true treatment of malaria than any other observer. He discovered that a combination of jalap and calomel had the effect of cutting short or preventing an attack. He bad it made up into pills which his followers called "Livingstone rousers," duly appreciating their drastic purgation. But Livingstone was unable to explain their action. After several years' study on African fevers I began to suspect that it was not in the blood we must look for the chief source of the poison but in the intestine. I was led to this belief partly by the facts I bave already stated in considering its pathology and by the inefficacy of quinine, partly by observing the benefit arising from "Livingstone rousers" and by my experiments on gastric malarias.

Experimenting with the drugs in "Livingstone rousers" I found that jalap had no effect on fever; with calomel I had a different result. I had already administered it as an antiseptic in malarial enteritis with marked success. At the time I did not base it on the theory I now hold, but for some time I had been convinced that mercurial compounds exerted a beneficial action on malaria. Calomel by combining both the properties of a stimulant of the intestinal glands and an antiseptic of the intestinal tract appealed to me as being peculiarly adapted to the objects of its treatment. It was therefore with considerable interest that I read in THE LANCET 1 Surgeon-Lieutenant-Colonel Duke's article on the Treatment of Asiatic Cholera by Calomel. There is a form of malaria which closely resembles Asiatic cholera ; indeed, it appears to me that there is a relationship between them. I found that calomel exerted the same beneficial action here as Surgeon-Lieutenant-Colonel Dake ascribed to it in Asiatic cholera. In that form of malaria where uncontrollable vomiting is the prominent symptom"the white romit"-its action was instantaneous. In the comatose form its effect was equally rapid, in the continued fevers it cut short the attack. In hyperpyrexia it immediately reduced the temperature. In agues it had the effect of at first confining the stages and then preventing them. In malarial pneumonia it had an extraordinary effect in controlling the spread of the inflammatory process in the lung and also reduced the temperature. Of course each case requires modification in its treatment, but usually I gave $3 \mathrm{gr}$. at first in cases in which there was constipation and $5 \mathrm{gr}$. in those in which laxity of the bowels was a prominent symptom. Twenty-four hours after I administered a smaller dose and if there was no severe purging in thirty-six hours a still smaller one. I always use calomel in powder as I find its action is more certain than in pills or tabloids. On no account is opium to be used. Dr. Webster Jones in an article in THE LANCET some years ago on the Value of Calomel in Asiatic Cholera pointed out the fatality following the administration of opium and I am convinced that the same is the case in malaria. Large saline draughts should not be given with calomel to hasten its action, but soda- and potash-waters in small quantities to quench the thirst and alkalise the plasma are necessary. In cases where paralysis of muscles is present or failure of heart threatened hot soup with large doses of pepper will be found of great advantage. I cannot recommend pepper too highly as a stimulant in malaria. I now turned my attention to those drugs which stimulate biliary secretion, such as podophyllin, rhubarb, colchicum, and euonymin. I was not long in discovering that they were injurious, showing that increased secretion of bile without proportional oxidation reacts unfavourably. This went far to prove my theory of intestinal absorption. But I went still further, for I have found fever to be induced by a full diet of meat and fats, which we know increases in a marked degree the secretion of bile and diminishes glycogen. In both ordinary attacks and those induced by diet the administration of calomel has the same beneficial effect. ' But, as I have 
said, it is not only necessary to destroy the laboratory of the poison in the intestine : we must also destroy it in the blood. It is not enough to stand by and wait till the poison is exhausted through the natural channels of excretion. It clings to the blood with a strange obstinacy and seemingly has the power after passing from the blood into the intestine to develop and reconstitute its laboratory. We might by the administration of calomel again cleanse the prime viae, but we do not prevent a fresh infection. No, we must attack it in the blood. In a method of treatment we find the true adaptation of the term specific. It is not enough to use such drugs as iron and carbonate of potash as we do in the anxmia of chlorosis. We have here no vital poison like malaria. Dr. Rustace Smith, in his work on the Diseases of Children, says that in malaria where there is much acute enlargement of the liver and spleen quinine seems to be useless and advocates a treatment with grey powder. I find that quinine has a more favourable action on the poison after the administration of calomel than without it, because probably calomel obviates the biliary derangements which are a feature of quinine. Here we find, I believe, the true and proper application of quinine. I experimented still further on several drugs said to have antiseptic properties on the blood, such as alicylic acid, arsenic, potassium iodide, and carbolic acid. I got the best results from carbolic acid, but better results still by a combination of carbolic acid and quinine. I gave it in the form of a solution in the proportion of $1 \mathrm{gr}$. of carbolic acid to $3 \mathrm{gr}$. of quinine in sulphuric acid and water to $1 \mathrm{oz}$. every four hours till the temperature fell, then less frequently for several days, till the symptoms had disappeared. Almost every case reacted favourably to this treatment. In my hands it has been practically specific. Arsenic is largely used in the French army, partly, I believe, from economical reasons, but the mortality among their troops in Madagascar is a sad proof of its inefficacy. Arsenic diminishes the glycogen of the liver and is thus another plank in favour of the glycogenic theory. In the after treatment the principal object is to nourish the patient, at the same time keeping close watch on the liver, regulating any derangement at once, keeping the paths of excretion open, and giving a diet largely consisting of carbohydrates. Alcohol must be sparingly indulged in; excess is fatal. Another point which is not generally known is that a sea voyage is unfavourable unless the patient is fully convalescent. H.R.H. Prince Henry of Battenberg died at sea; so did Sir William Maxwell. It is a common thing for men to come on board at Beira incompletely convalescent and die before they reach Natal. In many cases men completely convalescent succumb to the terrible black-water fever after being a few hours at sea. What the cause is it is difficult to say. Possibly the motion of the vessel acting through the nerve centres on the vasomotor nerves of the liver may disturb its glycogenic functions, or a chill may be the cause or it may be in the atmosphere itself. Whatever it may be, however, it is a law of malaria which it is well to bear in mind when advising a patient to take the voyage to Europe. It is too frequently the voyage from which none return.

Banchory, Kincardineshire, N.B.

\section{EXTRAORDINARY CASE OF HORSE-BITE;}

\section{THE EXTERNAL EAR COMPLETELY} BITTEN OFF AND SUCCESSFULLY REPLACED

\section{By WILliaM J. BROWN, B.A., M.B. DuB.,} L.R.C.S. IREL.,

CERTIFYING FACTORY SURGEON

ON March 2nd, 1898, at about 4.30 P.M., when present at an auction, I was asked to attend to a boy, aged fourteen years, whose ear had been bitten off by a vicious horse. He presented a hideous appearance, the greater portion of the pinna, together with a semi-circular flap of an inch radins from behind the ear, having been bitten off, leaving only the tragus with a quarter of an inch each of the helix and lobule. (See Fig. 1.) Although the case looked so hopeless (as regards disfigurement) I determined to make an attempt to save the ear, as the patient could be no worse off than be was then if the attempt failed. I

asked for the ear and after about ten minutes' search it was brought to me, having been found near the horse in the stable yard. It was of a dirty drab colour and the posterior flap was curled up in a roll. I had no instruments or dressings with me, and it would have taken half an hour or more to procure them, which delay would have

FIG. 1.

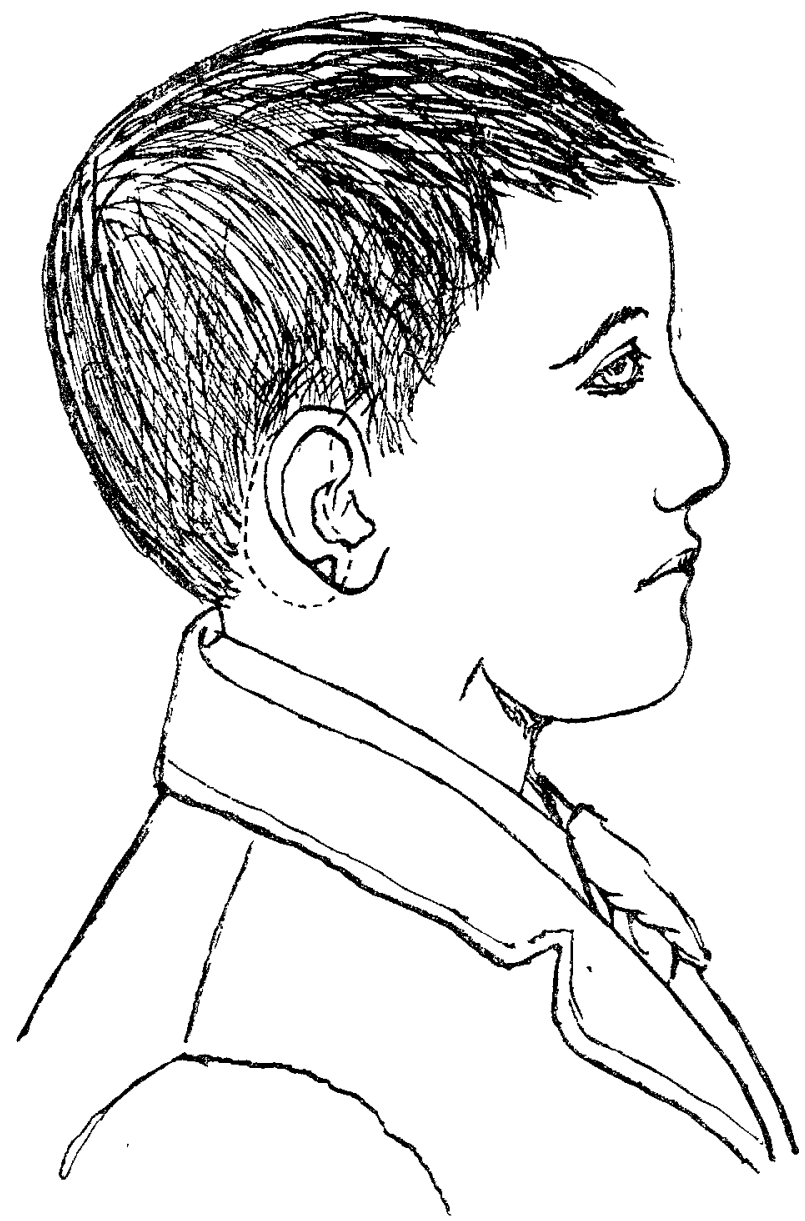

The dotted line indicates the portion of the pinna and tissues behind the ear which were bitten off. A notch in the lobe indicates the spot where sloughing took place.

FIG. 2.

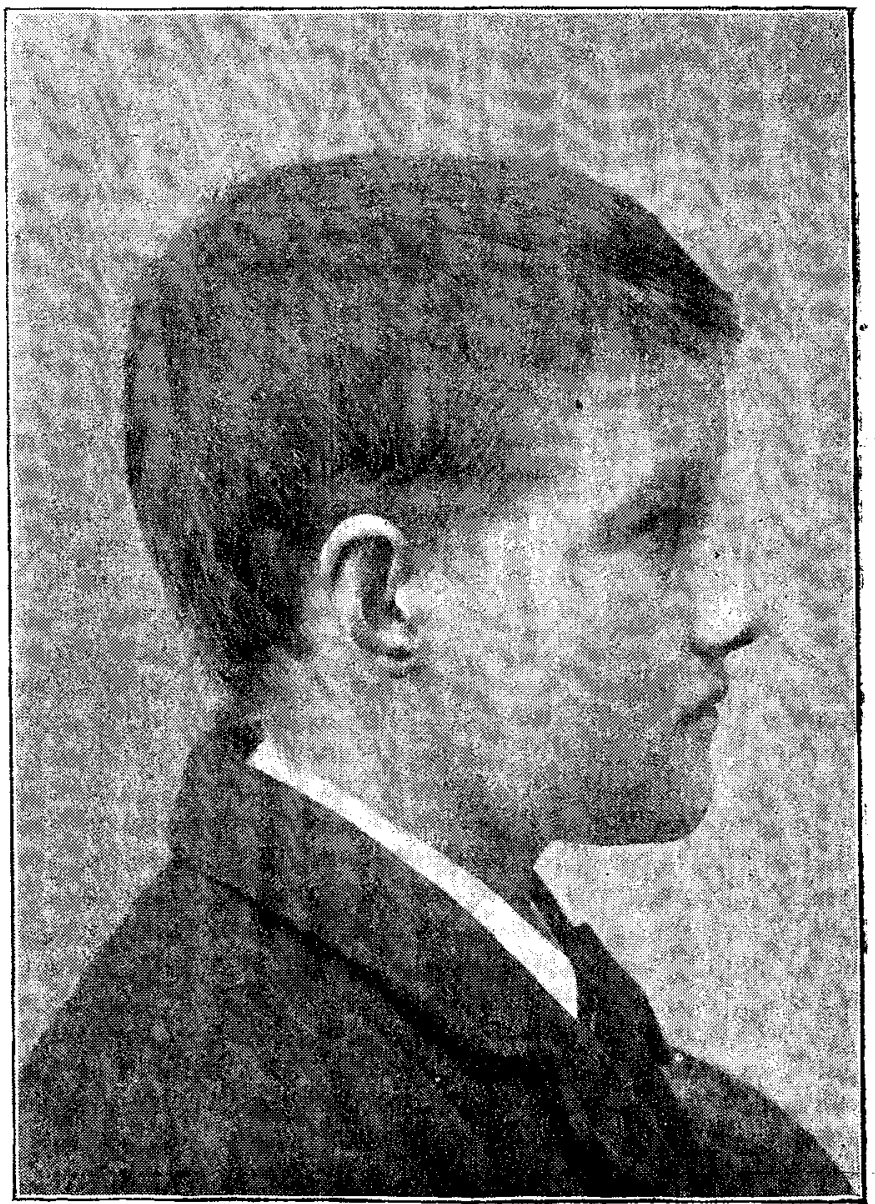

R. J-, aged fourteen years, as he now appears, 